\title{
Does use of pooled cohort risk score overestimate the use of statin?: a retrospective cohort study in a primary care setting
}

Yook Chin Chia ${ }^{1,2^{*}}$, Hooi Min Lim ${ }^{1}$ and Siew Mooi Ching ${ }^{3,4}$

\begin{abstract}
Background: Initiation of statin therapy as primary prevention particularly in those with mildly elevated cardiovascular disease risk factors is still being debated. The 2013 ACC/AHA blood cholesterol guideline recommends initiation of statin by estimating the 10-year atherosclerotic cardiovascular disease (ASCVD) risk using the new pooled cohort risk score. This paper examines the use of the pooled cohort risk score and compares it to actual use of statins in daily clinical practice in a primary care setting.

Methods: We examined the use of statins in a randomly selected sample of patients in a primary care clinic. The demographic data and cardiovascular risk parameters were captured from patient records in 1998. The pooled cohort risk score was calculated based on the parameters in 1998. The use of statins in 1998 and 2007, a 10-year interval, was recorded.

Results: A total of 847 patients were entered into the analysis. Mean age of the patients was $57.2 \pm 8.4$ years and $33.1 \%$ were male. The use of statins in 1998 was only $10.2 \%(n=86)$ as compared to $67.5 \%(n=572)$ in 2007 . For patients with LDL 70-189 mg/dl and estimated 10-year ASCVD risk $\geq 7.5 \%(n=190), 60 \%(n=114)$ of patients were on statin therapy by 2007. There were 124 patients in whom statin therapy was not recommended according to ACC/AHA guideline but were actually receiving statin therapy.

Conclusions: An extra 40\% of patients need to be treated with statin if the 2013 ACC/AHA blood cholesterol guideline is used. However the absolute number of patients who needed to be treated based on the ACC/AHA guideline is lower than the number of patients actually receiving it in a daily clinical practice. The pooled cohort risk score does not increase the absolute number of patients who are actually treated with statins. However these findings and the use of the pooled cohort risk score need to be validated further.
\end{abstract}

Keywords: Pooled cohort, Risk score, AHA/ACC, Statin, Primary care, Atherosclerotic cardiovascular disease risk, ASCVD, CV, Retrospective, Cohort, Malaysia

\section{Background}

Statins have been extensively studied both in primary and secondary prevention of cardiovascular events [1-4]. Identifying those who need statin therapy is crucial as we need to weigh the cardiovascular $(\mathrm{CV})$ risk against adverse events of drug therapy, so that under- or over-

\footnotetext{
* Correspondence: chiayc@um.edu.my

'Department of Primary Care Medicine, Faculty of Medicine, University of Malaya Primary Care Research Group (UMPCRG), University of Malaya, 50603 Kuala Lumpur, Malaysia

${ }^{2}$ Curtin Health Innovation Research Institute, Faculty of Health Sciences,

Curtin University, GPO Box U1987, 6845 Perth, WA, Australia

Full list of author information is available at the end of the article
}

treatment can be minimized. Therefore, cardiovascular risk stratification tools have been developed to help clinicians identify patients, particularly those with mildly elevated cardiovascular risk factors, who should be treated with statins [5].

Until recently, the NCEP ATP-III Framingham risk score was used as a tool to stratify risk for the indication of statin therapy [6]. In November 2013, the American College of Cardiology and American Heart Association (ACC/AHA) released a new guideline for the management of blood cholesterol [7]. Patients with clinical atherosclerotic cardiovascular disease (ASCVD) should 
receive statin therapy as secondary prevention. For primary prevention, ACC/AHA guideline recommends statin therapy for patients with LDL $\geq 190 \mathrm{mg} / \mathrm{dl}$. Statin therapy is also recommended for patients with diabetes mellitus and LDL 70-189 mg/dl. Patients without diabetes but with LDL 70-189 mg/dl and a 10-year ASCVD risk $\geq 7.5 \%$ based on the new pooled cohort risk score should be given statin. The pooled cohort risk equation was derived from pooled data of four large cohorts that included both white and black men and women (Framingham and the Framingham Offspring studies, Atherosclerosis Risk in Communities, Cardiovascular Health Study and Coronary Artery Risk Development in Young Adults).

Since the release of the 2013 ACC/AHA guideline there has been a lot of debate and concern about the use of this new pooled cohort risk score as it recommends a much lower threshold of $\geq 7.5 \%$ for the initiation of statins. Hence it is perceived to overestimate CV risk and that more patients will need to be treated with statin [8-10]. Currently, there are still very few studies exploring the use of the pooled cohort risk score in different populations. Hence, we examined the use of the pooled cohort risk score that identifies patients who need statin against patients who are actually receiving statin therapy in a daily clinical practice in primary care.

\section{Methods}

\section{Setting}

This current study is part of a 10-year retrospective cohort study of randomly selected patients registered with a primary care clinic. This clinic is an outpatient clinic of University Malaya Medical Centre, a teaching hospital in Kuala Lumpur, the capital city of Malaysia. This clinic is run by 14 family medicine specialists, 30 vocational trainees in family medicine and other medical officers. This tertiary medical centre including its primary care clinic serves a multi-ethnic population of 450,000 in the surrounding area. The majority of our study the population are middle class patients with around 11 years of formal education. They are also representative of the type of patients that are seen in primary care clinics in Malaysia. Ethics approval was obtained from the Ethics Committee of the University of Malaya Medical Centre.

\section{Study population}

This study is part of a retrospective cohort study for validating the Framingham Risk Score in a primary care Asian population. There were 970 patients in the original cohort and 908 were in the age group 40-75 years (the age group in whom the pooled cohort risk score is applicable according to the ACC/AHA guideline). After excluding patients with incomplete data on LDL level and statin use in 2007, 847 patients were eligible for this analysis.

\section{Inclusion criteria}

Adults aged 40-75 without clinical ASCVD who were already registered in our centre in 1998 were eligible for this study.

\section{Exclusion criteria}

Patients who did not have all the variables to calculate the pooled cohort risk score at baseline were excluded. Those patients with incomplete data on LDL level and statin use in 2007 were excluded as well.

\section{Data collection}

Random numbers were generated by computer based on the patients' registration number with the clinic. Baseline data was collected in 1998 and follow-up data collected in 2007, a 10-year interval. We extracted the patients' information from their paper-based records manually. Socio-demographic data and co-morbidities were recorded. Blood pressure was measured by the attending doctor using mercury sphygmomanometer as part of daily routine care. Diagnosis of hypertension in our clinic is made in accordance with standard recommendations i.e. blood pressure $\geq 140 / 90 \mathrm{mmHg}$ based on at least 2 blood pressure measurements at least 2 weeks apart [11]. Anti-hypertensive drug use was also recorded.

Diabetes mellitus was defined as documented by the attending physician or the use of hypoglycaemic agents or both. HbA1c levels of diabetic patients were also captured. Smokers were defined if they were still smoking currently. Non-smokers were those who never smoked or currently not smoking regardless of when they had stopped smoking. Renal function was determined by the estimated glomerular filtration rate (eGFR) based on the Cockcroft-Gault formula [12].

Total cholesterol, LDL and HDL cholesterol levels were captured. Statin use in 1998 and 2007 were recorded. We calculated the pooled cohort risk score for those without diabetes but with LDL $70-189 \mathrm{mg} / \mathrm{dl}$ using the online pooled cohort risk calculator provided by American Heart Association [13]. ASCVD events from 1998 until 2007 (10-year period) were collected. ASCVD events were defined as nonfatal myocardial infarction (MI), coronary heart disease (CHD) death, nonfatal and fatal stroke in accordance to the ACC/ AHA guideline.

\section{Statistical analysis}

All statistical analysis was done using the Statistical Package for Social Sciences (SPSS version 16). Categorical data are reported as proportions (percentage). Mean was used for continuous variables that were normally distributed. Median and interquartile range were used for variables that were not normally distributed. 


\section{Results}

847 patients who fulfilled the inclusion criteria were recruited into our analysis. Overall, the baseline mean age of the patients was 57.2 years with $33.1 \%$ male. Table 1 shows the cardiovascular risk profile in 1998 and 2007. Only 184 (8\%) of patients had chronic kidney disease stage 3 and above in 1998. $86(10.2 \%)$ of patients were on statin therapy in 1998 compared to 572 (67.5\%) in 2007.

Figure 1 shows the comparison of the ACC/AHA guideline to the use of statins in actual primary care practice. As patients with clinical ASCVD in 1998 were excluded, the first major recommendation group is patients with $\mathrm{LDL} \geq 190 \mathrm{mg} / \mathrm{dl}(\mathrm{n}=153) .90 .8 \%(\mathrm{n}=139)$ of our patients of this group were on a statin by the end of the 10 -year period. For patients with diabetes mellitus and LDL $70-189 \mathrm{mg} / \mathrm{dl}$, only $63.9 \%(\mathrm{n}=195)$ of diabetic patients were on statin.
For patients without diabetes but with LDL 70$189 \mathrm{mg} / \mathrm{dl}$, we estimated their 10-year ASCVD risk using the pooled cohort risk score to determine the indication for statin therapy. There were 190 patients with estimated 10 -year ASCVD $\geq 7.5 \%$. Only $60.0 \%$ $(\mathrm{n}=114)$ of these patients were receiving statin. Hence, an extra $40 \%(n=76)$ of patients with risk score $\geq 7.5 \%$ need to be treated with statins if the recommendations of the ACC/AHA guidelines were used. On the other hand, $62.3 \%(\mathrm{n}=124)$ of patients were receiving statin when it was not indicated based on 10-year ASCVD risk score.

A total of 35 (4.1\%) ASCVD events occurred over the 10 year period ( 31 non-fatal strokes, 1 fatal stroke and 3 non-fatal CHD) (Figure 1). 6.6\% of diabetic patients with LDL $70-189 \mathrm{mg} / \mathrm{dl}$ had ASCVD events. For those patients with LDL 70-189 mg/dl and estimated 10-year

Table 1 Cardiovascular disease risk profile for adults age of 40 and 75 years in 1998 and their profile in 2007

\begin{tabular}{|c|c|c|}
\hline All adults $(\mathrm{N}=847)$ & Year 1998 & Year 2007 \\
\hline Mean age - yr & $57.2 \pm 8.4$ & $67.1 \pm 8.4$ \\
\hline Age $<65(n, \%)$ & $672(79.3)$ & $340(40.1)$ \\
\hline Age $\geq 65(n, \%)$ & $175(20.7)$ & $507(59.9)$ \\
\hline Male sex (n, \%) & $280(33.1)$ & $280(33.1)$ \\
\hline \multicolumn{3}{|l|}{ Ethnicity (n, \%) } \\
\hline Malay & $191(22.6)$ & $191(22.6)$ \\
\hline Chinese & $389(45.9)$ & $389(45.9)$ \\
\hline Indian & $256(30.2)$ & $256(30.2)$ \\
\hline Others & $11(1.3)$ & $11(1.3)$ \\
\hline Mean BMl & $26.5 \pm 4.64$ & $26.1 \pm 4.7$ \\
\hline Low-density lipoprotein $\geq 190$ mg/dl (n, \%) & $153(11.5)$ & $14(1.7)$ \\
\hline \multicolumn{3}{|l|}{ Cholesterol } \\
\hline Median total - mg/dl (IQR) & $232.0(208.8-259.1)$ & $189.5(166.3-216.6)$ \\
\hline Median low-density lipoprotein - mg/dl (IQR) & $158.2(133.2-181.0)$ & $113.3(92.0-136.2)$ \\
\hline Median high-density lipoprotein - mg/dl (IQR) & $46.4(38.7-54.1)$ & $48.0(40.8-56.8)$ \\
\hline Mean systolic blood pressure - $\mathrm{mmHg}$ & $140.4 \pm 18.3$ & $135.0 \pm 16.6$ \\
\hline Mean diastolic blood pressure - $\mathrm{mmHg}$ & $84.65 \pm 10.1$ & $78.8 \pm 8.2$ \\
\hline Patients on antihypertensive agent $(n, \%)$ & $503(59.4)$ & $735(86.6)$ \\
\hline Diabetes mellitus (n, \%) & $379(44.7)$ & $508(60.0)$ \\
\hline Mean HbA1c - \% & $7.73 \pm 1.8$ & $7.66 \pm 1.6$ \\
\hline Current smoking (n, \%) & $61(6.0)$ & $61(6.0)$ \\
\hline Mean creatinine - umol/L & $79.8 \pm 23.7$ & $85.2 \pm 40.8$ \\
\hline Mean eGFR- $\mathrm{ml} / \mathrm{min}$ per $1.73 \mathrm{~m}^{2}$ & $78.1 \pm 26.2(n=779)$ & $67.8 \pm 27.0(n=663)$ \\
\hline$<30(\mathrm{n}, \%)$ & $5(0.6)$ & $32(3.8)$ \\
\hline $30-60(n, \%)$ & $179(21.1)$ & $254(30.0)$ \\
\hline$>60(n, \%)$ & $595(92.0)$ & $377(44.5)$ \\
\hline Use of statins (n, \%) & $86(10.2)$ & $576(67.5)$ \\
\hline
\end{tabular}

IQR Interquartile range. 
ASCVD risk $\geq 7.5 \%, 3.2 \%$ had ASCVD events in the 10 years. The pooled cohort risk score overestimated the ASCVD risk in our study population. For those patients in whom statin therapy was not recommended $(n=199)$, 5 ASCVD events occurred (2.5\%).

\section{Discussion}

Clinicians frequently face a dilemma when deciding on statin initiation as primary prevention, particularly in those without diabetes and those with apparently mildly elevated cardiovascular disease risk factors when the indication is less clear and evidence less strong. The recent ACC/AHA guideline suggests patients should be treated with statins if their pooled cohort risk score is $\geq 7.5 \%$. This lower threshold for initiating statin treatment in contrast to the higher threshold used previously would suggest that many more patients will need to receive statins and that overtreatment will occur. This is of concern particularly as a recent report suggests that subjects with lower risk actually derive no benefit but have more harm from treatment with statins [14]. However the recently updated NICE guidelines also supports initiating statin therapy at lower CV risk i.e. $\geq 10 \%$ albeit using the new QRISK2 score and not the AHA/ACC pooled cohort scoring system. The NICE recommendation has also been supported by others $[15,16]$.

Based on our study, an extra $40 \%$ of patients $(n=76)$ will need to be treated if the pooled cohort risk score was used. This is consistent with a study on use of the 2013 ACC/AHA guideline in the American population based on National Health and Nutrition Examination Survey (NHANES III) where an extra $15.9 \%$ of patients, equivalent to 12.8 million more people will need to be treated with statins when compared with the ATP III guidelines [8]. Another study also using the ACC/AHA guideline in a non-American population in Netherlands showed that more adults will also need statin therapy whereby nearly all men and two thirds of women will need to be treated [9].

However in our cohort of patients, we found that more than half of patients $(62.3 \%, \mathrm{n}=124)$ were actually receiving statin when statin therapy would not have been indicated based on the new pooled cohort risk score recommendations at baseline. However their statin therapy may have been started because they developed diabetes, hypertension or dyslipidaemia which would have increased their $\mathrm{CV}$ risk, sometime in the 10 years of follow-up. 
Interestingly the number of patients treated "unnecessarily" with statins in actual clinical practice $(\mathrm{n}=124)$ is even higher than the extra number of patients who need to be treated based on recommendations of the new AHA/ACC guideline $(n=76)$. On balance, the total number of patients recommended by the ACC/AHA guidelines did not exceed the number of patients who were actually receiving statin in real-life daily clinical practice in primary care where most of the lower to moderate risk patients are seen. Perhaps the pooled cohort risk score can guide clinicians in identifying the correct patients for statin therapy, thus avoiding overor under-treatment. Johansen et al. also pointed out that the pooled cohort risk score may guide the clinicians to focus on patients' $\mathrm{CV}$ risk when initiating statin therapy instead of the lipid profile alone and hence avoid undertreatment in high risk people [17].

According to the NCEP ATP III guidelines, diabetes mellitus is considered a cardiovascular heart disease (CHD) risk equivalent [18]. Clearly this group of patients has high cardiovascular risk and statin therapy will be of benefit to them [19-21]. Our study has also shown that not all patients with diabetes mellitus were receiving statin therapy and this is consistent with findings in other studies [17,22]. Greater effort will be needed to get all patients with diabetes to be on statin therapy.

The pooled cohort risk score is meant to be used to stratify risk for initiation of statin therapy. Although our patients were not risk scored in 1998 for statin use, 60\% of them deemed to need statin were eventually receiving some time over the 10 year period. This implies that the use of the risk score identifies patients earlier to receive statins and therefore could be helpful to clinicians in deciding when to start statin.

\section{Strengths and limitations}

A strength of our study is that it is done in a primary care clinic where most patients who are at lower risk for CVD are seen. These are the very same patients in whom initiation of statin therapy as primary prevention is less clear and is when a global CVD risk is most helpful to stratify risk for statin therapy. Furthermore the period studied is relatively long and allows tracking of the use of statin over 10 years. Our study also reflects true clinical practice of the use of statin in primary care. There are several limitations in our study. Firstly, patients with incomplete data, especially HDL cholesterol level which is an important factor in the pooled cohort risk equation, were excluded in this analysis. We also do not have data on when statin was initiated. However patients who needed statins did eventually receive statins some time in the 10 -year period.

\section{Conclusions}

An extra $40 \%$ of patients need to be treated with statin if 2013 ACC/AHA blood cholesterol guideline is used. However the absolute number of patients needed to be treated based on the ACC/AHA guideline is lower than the actual number of patients who were receiving it in daily clinical practice. The pooled cohort risk score may serve as an appropriate tool to guide clinicians on the initiation of statin therapy. However, further studies are needed to validate the pooled cohort risk equation.

\section{Abbreviations}

ASCVD: Atherosclerosis cardiovascular disease; ACC/AHA: American College of Cardiology and American Heart Association; NCEP ATPIII: National Cholesterol Education Program Adult Treatment Panel III; CV: Cardiovascular; HDL: High density lipoprotein; LDL: Low density lipoprotein; DM: Diabetes mellitus; BP: Blood pressure.

\section{Competing interests}

The authors declare that they have no competing interests.

\section{Authors' contributions}

CYC contributed to the conceptualizing the paper, data entry and writing of the manuscript while LHM and CSM contributed data analysis and writing of the manuscript. CYC is the corresponding author. All the authors read and approved the final manuscript.

\section{Acknowledgements}

The author would like to acknowledge University Malaya for providing the research grant (UMRG 116/09HTM) and Department of Primary Care at the University of Malaya for providing the support during the data collection.

\section{Author details}

1Department of Primary Care Medicine, Faculty of Medicine, University of Malaya Primary Care Research Group (UMPCRG), University of Malaya, 50603 Kuala Lumpur, Malaysia. ${ }^{2}$ Curtin Health Innovation Research Institute, Faculty of Health Sciences, Curtin University, GPO Box U1987, 6845 Perth, WA, Australia. ${ }^{3}$ Department of Family Medicine, Faculty of Medicine and Health Sciences, Universiti Putra Malaysia, 43400 Serdang, Malaysia. ${ }^{4}$ Department of Gerontology, Universiti Putra Malaysia, 43400 Serdang, Malaysia.

Received: 16 July 2014 Accepted: 6 October 2014

Published online: 12 November 2014

\section{References}

1. Law MR, Wald NJ, Rudnicka AR: Quantifying effect of statins on low density lipoprotein cholesterol, ischaemic heart disease, and stroke: systematic review and meta-analysis. BMJ 2003, 326(7404):1423.

2. Vrecer M, Turk S, Drinovec J, Mrhar A: Use of statins in primary and secondary prevention of coronary heart disease and ischemic stroke. Meta-analysis of randomized trials. Int I Clin Pharmacol Ther 2003, 41(12):567-77.

3. Hebert PR, Gaziano JM, Chan KS, Hennekens CH: Cholesterol lowering with statin drugs, risk of stroke, and total mortality. An overview of randomized trials. JAMA 1997, 278(4):313-21.

4. Thavendiranathan P, Bagai A, Brookhart MA, Choudhry NK: Primary prevention of cardiovascular diseases with statin therapy: a meta-analysis of randomized controlled trials. Arch Intern Med 2006, 166(21):2307-13.

5. Chia YC: Review of tools of cardiovascular disease risk stratification: interpretation, customization and application in clinical practice. Singapore Med J 2011, 52(2):116.

6. D'Agostino RB, Vasan RS, Pencina MJ, Wolf PA, Cobain M, Massaro JM, Kannel WB: General cardiovascular risk profile for use in primary care: The Framingham heart study. Circulation 2008, 117:743-753.

7. Stone NJ, Robinson JG, Lichtenstein AH, Bairey Merz CN, Blum CB, Eckel RH, Goldberg AC, Gordon D, Levy D, Lloyd-Jones DM, McBride P, Schwartz JS, Shero ST, Smith SC Jr, Watson K, Wilson PW: 2013 ACC/AHA guideline on the treatment of blood cholesterol to reduce atherosclerotic 
cardiovascular risk in adults: a report of the American College of Cardiology/American Heart Association Task Force on Practice Guidelines. Circulation, [published online November 12, 2013]. doi:10.1161/01. cir.0000437738.63853.7a.

8. Pencina MJ, Navar-Boggan AM, D'Agostino RB Sr, Williams K, Neely B, Sniderman AD, Peterson ED: Application of new cholesterol guidelines to a population-based sample. NEJM 2014, 370(15):1422-1431.

9. Kavousi M, Leening MJG, Nanchen D, Greenland P, Graham IM, Steyerberg EW, Ikram MA, Stricker BH, Hofman A, Franco OH: Comparison of application of the ACC/AHA guidelines, adult treatment panel III guidelines, and europeon society of cardiology guidelines for cardiovascular disease prevention in a european cohort. JAMA 2014, 311(14):1416-1423.

10. Ioannidis JP: More than a million people taking statins? Potential implications of the new cardiovascular guidelines. JAMA 2014, 311(5):463-464.

11. Chobanian AV, Bakris GL, Black HR, Cushman WC, Green LA, Izzo JL, Jones DW, Materson BJ, Oparil S, Wright JT Jr, Roccella EJ: Seventh report of the joint national committee on prevention, detection, and treatment of high blood pressure. Hypertension 2003, 42(6):1206-1252.

12. Poggio ED, Wang $X$, Greene T, Van Lente F, Hall PM: Performance of the modification of diet in renal disease and Cockcroft-Gault equations in the estimation of GFR in health and in chronic kidney disease. J Am Soc Nephrol 2005, 16(2):459-466.

13. Goff DC Jr, Lloyd-Jones DM, Bennett G, Coady S, D'Agostino RB Sr, Gibbons R, Greenland P, Lackland DT, Levy D, O'Donnell CJ, Robinson JG, Schwartz JS, Shero ST, Smith SC Jr, Sorlie P, Stone NJ, Wilson PW: 2013 ACC/AHA guideline on the assessment of cardiovascular risk: a report of the American College of Cardiology/American Heart Association Task Force on Practice Guidelines. Circulation. [published online November 12, 2013]. doi:10.1161/01.cir.0000437741.48606.98.

14. Abramson JD, Rosenberg HG, Jewell N, Wright JM: Should people at low risk of cardiovascular disease take a statin? BMJ (Clinical Research Ed) 2013, 347:f6123.

15. Rabar S, Harker M, O'Flynn N, Wierzbicki AS: Lipid modification and cardiovascular risk assessment for the primary and secondary prevention of cardiovascular disease: summary of updated NICE guidance. BMJ (Clinical Research Ed) 2014, 349:94356.

16. Hawkes N: Six professors back NICE guidance on extending use of statins. BMJ (Clinical Research Ed) 2014, 349:94380.

17. Johansen ME, Green LA, Sen A, Kircher S, Richardson CR: Cardiovascular risk and statin use in the United States. Ann Fam Med 2014, 12(3):215-223.

18. National Heart Lung and Blood Institute: Third report of the National Cholesterol Education Program (NCEP) expert panel on detection, evaluation, and treatment of high blood cholesterol in adults (Adult Treatment Panel III) final report. Circulation 2002, 106(25):3143-421.

19. Colhoun HM, Betteridge DJ, Durrington PN, Hitman GA, HA WN, Livingstone SJ, Thomason MJ, Mackness MI, Charlton-Menys VH, Fuller J: Primary prevention of cardiovascular disease with atorvastatin in type 2 diabetes in the collabrative atorvastatin diabetes study (CARDS): multicentre randomised placebo-controlled trial. Lancet 2004, 364(9435):685-696

20. Collins R, Armitage J, Parish S, Sleigh P, Peto R: MRC/BHF heart protection study of cholesterol-lowering with simvastatin in 5963 people with diabetes: a randomised placebo-controlled trial. Lancet 2003, 361(9374):2005-2016.

21. Vijan S, Hayward RA: Phamacologic lipid-lowering therapy in type 2 diabetes mellitus: background paper for American Collage of Physicians. Ann Intern Me 2004, 140(8):650-658

22. Foon $\mathrm{TS}$, Chin $\mathrm{CY}$, Chinna $\mathrm{K}$ : Rate of decline of kidney function in patients with type 2 diabetes mellitus and the associated factors a 10-year retrospective cohort study. Asia Pac J Public Health 2013. doi:10.1177/ 1010539513490193.

doi:10.1186/s12875-014-0172-y

Cite this article as: Chia et al:: Does use of pooled cohort risk score overestimate the use of statin?: a retrospective cohort study in a primary care setting. BMC Family Practice 2014 15:172

\section{Submit your next manuscript to BioMed Central and take full advantage of:}

- Convenient online submission

- Thorough peer review

- No space constraints or color figure charges

- Immediate publication on acceptance

- Inclusion in PubMed, CAS, Scopus and Google Scholar

- Research which is freely available for redistribution 